\title{
Corrigendum \\ Modulation of Social Influence by Methylphenidate
}

Daniel K Campbell-Meiklejohn, Arndis Simonsen, Mads Jensen, Victoria Wohlert, Trine Gjerløff, Jørgen Scheel-Kruger, Arne Møller, Chris D Frith and Andreas Roepstorff

Neuropsychopharmacology (2012) 37, 1973; doi:10.1038/npp.2012.26

Correction to: Neuropsychopharmacology (2012) 37, 1517-1525; doi:10.1038/npp.2011.337; published online 8 February 2012

In this article, there is an error in the last sentence of the abstract. The sentence should be as follows: We provide a new working hypothesis of a neurocognitive mechanism by which MPH reduces socially disruptive behavior. We also provide novel evidence of catecholamine mediation of social learning. 